\title{
Towards the Relationship between Social Welfare and Sustainable Development of Society
}

\author{
Lubov Ivankina \\ DSc, Professor, Department of Management, Senior Research Scientist, Elderly People's Well-Being \\ Improvement Technologies International Lab,Tomsk Polytechnic University; Email:ivankina@tpu.ru
}

\section{Ekaterina Anikina}

Ph.D, Assoc. Prof., Department of Economics, Tomsk Polytechnic University, Email: anikinaea@tpu.ru

\author{
Doi:10.5901/mjss.2015.v6n6s5p128
}

\begin{abstract}
The paper presents the relationship between social welfare and sustainable development of society. The purpose of this paper is to show that the social development is becoming more and more dependent upon valuable parameters that form the locus of the civil society movement. It is stated that mankind is able to influence the future through the choice of the optimum route of development. In this regard, the understanding of personal aspects of sociogenesis and its functioning mechanism is required as well as the understanding of differences between the social and natural dynamics. That is why, the philosophical understanding of sustainable development by means of social welfare as a regulatory mechanism, is one of the approaches to a study of regularities of the social life and development. The model of the social and practical existence oriented, in the first place, towards the satisfaction of needs, is the basis for the analysis of relationships between social welfare and sustainable development. A call for this aspect is especially significant for the modern society, since the consumption of goods develops from a simple use to a design instrument of the social identity and sociocultural integration of persons in society. Welfare is considered herein as a multifactor construct represented by the synthesis of cause and effect. The explication technique, hermeneutical approach and comparative analysis are used in this research.
\end{abstract}

Keywords: social welfare, sustainable development, existential world, welfare types, moral choice.

\section{Introduction}

At present, the relevance of scientific interest in the problem of social welfare is conditioned by a shift of paradigms and principles of the quality assurance in human life in terms of the increasing instability of the modern world. Different research trends are unified by a search for the integrating indicators and economic, socio-political, and moral reference points of the human and social evolution. The modern approach includes a search for a balance between the dominated economic-centrist and the ignored cultural-centrist approaches. The current situation is connected rather with the synthesis than separation or refusal from one in favor of another, and with the need for a comprehensive approach to modern problems.

A. Toffler was one of the first philosophers who indicated the problem of social welfare and the possibility of sustainable development in investigating survival strategies under conditions that 'The answer to future shock is not nonchange, but a different kind of change' (Toffler, 2002), when the development of the scientific scope 'threatens to alter not merely the 'how' of production but the 'why" (Toffler, 2002).

In this context, the idea of social welfare is directly connected with the idea of sustainable development oriented towards the provision of the choice of challenges that create the optimum proportions and equal life opportunities for the current and future generations and are safe, first of all, for the perspective survival of mankind. Helen Clark, the convenor of the United Nations Conference on Sustainable Development, also known as Rio+20, noted that 'justice, dignity, happiness, sustainability are significant for our life, however, absent in the GDP' (Rio+20, 2014).

A. Whitehead stated that 'civilization must regulate relational connections between people and the surrounding world in a way that will provide phenomena in which the dominant is the imperative harmony of stable things' (Whitehead, 1990). Is it possible to refer welfare to stable things?

For the answer, let us address to the problem of survival. In order to survive, the society must solve minimum three problems: to satisfy man's needs and develop the production; to provide the recovery of utilized resources; to pursue the 
policy of prevention and protection of socioeconomic turbulence from the inside. These problems can be solved in terms of interconnection between welfare and sustainability acting as basic values and ideas of the human society.

\section{Objectives, Methodology and Stages of the Research Project}

This research focuses on the determination of the following: place and role of social welfare in the development of mankind; welfare nature; relationship between social welfare and sustainability, and theoretical constructs of the relationship model.

The research methodology is based on the systems approach applied to the analysis of complex social and moralethical phenomena. The main idea of this methodology that allows conducting a mutually complimentary and consistent analysis of these processes, is the model used as a target structural description of the object under review. With this purpose, the approaches to the definition of such notions as welfare and sustainable development have been analyzed and their key parameters highlighted allowing the creation of the logical research model which is underlain by the model of everyday practices.

The principle of the system determination considers the multi-dimensional world as the integral system within the subjective perception of the objective reality that has a definite sense for an individual. Thus, the social welfare and sustainable development is the complicated functional system of relations that integrates specific values, purposes, intentions, and the general program of the instrument-meaning support and implementation of one or another relation under the particular behavioral and activity conditions.

The welfare parameters form a complex functional system of subject-object relations that integrates particular values, purposes, intentions at the level of the individual and society on the whole. This idea is substantiated by $\mathrm{J}$. Habermas (Habermas, 1995) in his concepts of Life World vs. System World. Each dimension of the individual's life space corresponds to the particular subject-object relation to different realms of being that reflect the qualitative parameters and state the correspondence of vitality to the life space in which the individual implements his/her plans in real time and place.

In the model, the source of activity and development transfers to intersystem relations, their specificity is observed through the emotional and assessing basics that add a differently directed nature to the subject activity. A subject that acts, self-determines at a time in relation to both the internal (intentions, wishes) and external necessity which also acts as the internal one. The interconnection and combination of these components determine the degree of implementation of individual needs, stability of the individual's social status, life satisfaction, etc.

A study of the problem of relationship between social welfare and sustainability is based on the principles of diversification, multiplicity of relations and descriptions, multidimensionality, hierarchy, development.

This research is implemented in a number of stages, namely: the analysis and generalization of modern approaches to a study of social welfare and sustainable development; detection of methodological establishments for modeling the relationship between social welfare and sustainable development; the relationship model validation.

\section{Notions of Welfare and Sustainability}

Aristotle was one of the first philosophers who noticed the diversity of understanding of the term welfare stipulated, first of all, by its multiple-factor construct represented by a synthesis of cause and effect. What is the relation and what are cause and effect of welfare?

Welfare cause lies in the necessity of overcoming a need for something, i.e. the satisfaction of needs, whereas its effect is saturation and satisfaction from the accomplishment. This interconnection is traced at the etymological level of a broad conceptual construct relating to the term welfare, which includes the broad context of social existence. Social welfare is, concurrently, the objective and subjective phenomenon determined by everyday conditions of vital activity under which people satisfy their needs, implement plans and social expectations.

Traditionally, understanding of the term welfare is connected with the state of society, which possesses all necessary facilities for the life support. Objective and subjective properties of man's existence are described by many notions among which are such as satisfaction, life satisfaction, quality of living, welfare, happiness, etc. This understanding of the term welfare allows concluding that it serves as a socio-personal ideal, which can be achieved by specific means. A subjective personal component reflects the concrete historical tension and social aspirations to the social order, and is charged with a choice of many prospects relating to certain resources and technologies of achieving new desirable social conditions.

To summarize definitions stated above, three aspects can be emphasized in understanding of the welfare notion. 
First, it means satisfaction with the life and is connected with its standards. It is also a global assessment of the quality of living in conformity with social and personal criteria. In these terms, welfare is a coincidence of satisfaction of needs and aspirations with really achieved ones or with what a person possesses in a real situation. Second, it implies the existence of a certain welfare standard. This understanding is 'recorded' in the requirements for moral life conditioned by the correspondence to the value system accepted in a certain culture at a certain historical age or time. Third, understanding of the welfare standard is further reflected by a subjective experience in reality that is fixed by the notion of happiness.

Social welfare is not only the available conditions and resources but also the human activity related to his/her own opportunities of posing and implementing life goals and the welfare potential.

The term sustainability is a synthesis of concepts of changes and stability, and expresses real dialectical contradictions and a tendency to their harmonization. The ontological character of these contradictions is defined by the scope of social existence. Sustainable development is the development, which satisfies the current needs and allows future generations to satisfy their own needs. These terms are possible to imply following the imperatives of sustainability, that include the system of valuable orientations and preferences allowing the choice of those decisions that provide equal opportunities in optimum proportions for the life of current and future generations taking into account, first of all, the perspective survival of mankind.

In this regard, the model of everyday practices is presented by the model of investigation of the relationship between social welfare and sustainable development of society that reflects the active and subjective logic of the history. The idea of everyday life is reflected by a range of concepts developed by P. Bourdieu (Bourdieu, 1995). He characterizes the everyday world through the concept of habitus, i.e. the system of definite practices that express the main dispositions (preferences, aptitudes, tastes) in relation to subjects, values, ideas, and so on. P. Bourdieu interprets habitus as the everyday practices organized by a man including not only the human behavior but emotions as well (Bourdieu, 1995).

Today, research of the welfare problems often focuses on a correlation between the outer and inner factors and their relationships that influence the formation and support of the optimum level of welfare. What this approach is stipulated by? First of all, welfare is a complex social phenomenon both in its nature and destination and application. The welfare phenomenon is recorded by the dialectic of 'realities' and 'universalities' that force the individual to trace the forms of appearance of the common in the specific in which and by which it exists.

A study of everyday practices allows understanding whether the individuals possess the needs for everyday life self-organization, what are they expressed by, and what are the institutional forms of their satisfaction.

\section{Social Welfare in the Context of Everyday Practices}

P. Sztompka first paid attention to the paradigmatic shift to the social existence in the focus of which the everyday life is found (Sztompka, 2009). The human involvement in everyday practices enables the processes of a man-environment metabolism, which has the origins of support and provision of all forms of natural and socio-cultural life.

According to P. Bourdieu, everyday practices are the content and the outcome of the activity of subjects (Bourdieu, 1995), i.e. social actions, communication between people, and social forms created by practices. As he noticed, practices are the implementation of social structures (Bourdieu, 1995). Welfare in social practices is a regulatory mechanism of socially important processes affecting life situations and vital activity. The welfare phenomenon records a socially important outcome that touches the human interests (economic, political, social, ecological, biological, cultural, information, moral, etc.) and the inhabitable environment.

A life situation is a combination of events and circumstances valuable or 'involved' in the human vital activity, which influence directly or indirectly his/her world-view and behavior at each given period of life. While organizing the inhabitable environment, solving important problems, a man spends his intellectual, emotional, and physical energies. At the same time, the inhabitable environment is not reduced to one or another sphere of activity (labour, life, self-service, leisure, etc.). Human spheres of activity as well as the social life (economy, politics, ecology, culture, etc.) are connected with each other through an individual. So, events occurred in one sphere affect on all other ones. In the course of the interaction and communication, the social subjects form local and global sociocultural realms in which examples, standards, rules, values are fixed to organize the life at a level of the individual and collective subject. Everyday practices are connected with three important notions in the lifestyle categories, namely quality, style, and course of life.

Life conditions that determine mostly everyday practices of individuals assist in the understanding of their behaviors and activities not in the direct way but through the perception structures and such its elements as needs, interests, valuable orientations. The individual and specific coordinates are given for a man by reasons, values, objectives that define the selected actions and priorities depending on their own intentions. It is the valuable-reasonable factor that 
defines such welfare parameter as width, in which an individual includes the notion referred to the category of valuable.

At the objective level, social welfare is connected with the experience of the content fullness, conciseness and life value on the whole as a means of achieving personal purposes(Dieneret. al., 2005) and the expectation of what should be achieved. E. Diener notes that a study of social welfare has to account not only for its level measured directly, but also the internal, individual system of coordinates (Diener et. al., 2005). The width of the notion welfare, integration of the life success and human activity in the different spheres requires a flexible, adaptive behavior as a formula for the successful and adequate behavior in diverse life situations.

Using different types of valuable orientations and motivations, one can ascertain the type of subjective welfare, its modus complexes. The material wealth modus is closely connected with the physical substructure of a person. It assumes a personal significance of material wealth and, first of all, the degree of its completeness. The self-determination modus includes the system of implementation of personal meanings, the life scenario of what should be determined depending on the conditions of socialization. The personal identity modus includes the system of ties and relations qualified as necessary and appropriate for retention of the internal equilibrium. The personal (characterological) welfare modus refers to the subjective assessment of the personal character and traits from the viewpoint of their acceptability by a wide variety of personal phenomena (from relationships with others to self-relation; from labour to inaction). The professional identity and career achievements modus includes the adequacy of professional identity, satisfaction with the occupation, labour, relationships in a collective body, etc. The physical and psychological health modus comprises the belief system of health value and defines the activity oriented towards the optimization of healthy living and health improvement.

In order to correspond to the living space, a man must adapt to it that means man's alteration. A complex mechanism of interference of personal (subjective) and eco-socio-cultural (objective) determinants takes place, which predetermine one or another result of the diversity of interactions between man and environment. The mode of life is a directed, continuous process within which already known models of way out are reproduced and alternated with the formation and initiation of new, unknown ways emerging in practices of the human existential world.

The inhabitable environment includes at least, four measurement aspects: natural, man-made, informational, and psychosocial-anthropological (other people with their life style, mentality, world view, personal traits, etc.).

Equally multidimensional is the socio-practical existing of a person, on the one hand, in the variety of temporal pulses corresponding to the astronomical, historical-cultural, psychological, biological time and in the coordinate system responsible for the main types of human activity and the direction of human efforts on the other, namely: socio-ecological (life reproduction), socio-economic (resource recovery), socio-cultural (living standard recovery). A man desires to be healthy, active, able to cope with difficulties of the world around and achieve his/her own goals, supported by other people and many other things that compose his/her basic expectations concerning the idea of well-being in the real world. The formation of the environment is directed to its alteration such that it would suit to a man. The choice of the environment is a search for new living conditions. While mastering the environment, a man involves in it himself, i.e. the state and direction of his/her consciousness and motto.

The formation of the meaning component of social welfare is based on the emotional assessment because welfare relates, first of all, to the individual assessment of what he/she possesses and how relates to it. The integral cognitive emotional assessment is presented by the satisfaction as a measurable indicator. Satisfaction was first measured by Aristotle who connected welfare with the phenomenon of happiness. In the human history, the problem of happiness is one of the key, existential topics directed to a search for understanding of the meaning of a human being. The phenomenon of happiness is considered within the different aspects including the life satisfaction, social welfare, love for one's neighbors, good luck, and belief. Social welfare is considered as a basic subjective construct that reflects the apprehension and assessment of its functioning from the viewpoint of the top of man's potential opportunities. This approach indicates to a great role of valuable and meaning orientations of a person in his/her own welfare or ill-being.

Having determined the achievement of happiness as the aim of a human being, Aristotle determined the origins of its achievement as well, namely, conditions without which happiness remains potential, but not experienced. One of the foremost origins of happiness is experience in pleasure.

Then arise questions of how to reach the emotional comfort; is it possible to be happy among the ill-being of other people; how to assure the stability of welfare? A search for the answers is connected with the ideas of social equality, social welfare, and the governmental responsibility for its provision.

The answer to the question of how to provide and implement the welfare phenomenon is found almost simultaneously with the understanding of its origins. The moral aspect was introduced in the understanding of the welfare nature, that defines welfare through the implementation of moral virtues. The understanding of welfare in the context of the moral-ethical approach is carried out by means of notions welfare and virtue. Welfare is considered herein as the 
major origin, the main cause of welfare, and connected with good. Virtue is interpreted as a collection of personal moral merits assisting in the achievement of welfare.

Social welfare is identified by the result of the coordinated social behavior and efficient interaction. It is considered as the objective phenomenon of the social life and analyzed at a societal level when the society is considered as an integrated scheme including the collection of functionally interconnected elements, in which social welfare provides the progressive development of the entire society and stable functioning of its components. By D. Durkheim,social welfare is the best public organization based on the social solidarity that exists due to the common recognition and implementation of social facts represented by standards, ideas, values generated by the collective consciousness of people (Durkheim, 1995). The main term of social welfare is the social order.

The society itself generates threats to human welfare that is demonstrated by the level of law infringement, social anomia, etc. The society with the low standard of living is forced to exist in contrast to the ideas of sustainability, since the absence of efficient technologies leads to inefficient production. And under in thelack of means of living, a man has to think about the future day for himself rather than for other people. Therefore, the growth of social welfare and sustainability should be provided by the social process management oriented towards the formation of favourable social and economic conditions under which the individuals can achieve both own and social welfare through personal and cooperative labourso as to prevent the society from an inward explosion induced by relationships between people.

\section{Welfare as a Factor of Sustainability}

Diversification of needs depending on different objective circumstances (historical time, governmental priorities, technological change, personal development) leads to instability of the social existence which is mostly evaluated just by social welfare, the indicator of a sustained interaction between man, society, and culture.

On the one hand, the welfare implementation includes intentions and life strategies of people who solve problems of everyday practices that satisfy needs using own existential resources they possess (from physical to spiritual including personal traits). On the other hand, it includes counterflows of institutionally supported strategies of those who hold public resources (governmental, departmental, regional, municipal, private).

The achievement and retention of a certain social state fixed by the notion health is important from the point of view of welfare. E. Fromm suggested to apply the social analysis to the health criterion which was fixed in the category of sane society. Later, this concept was applied by Toffler in his book 'Future shock' (Toffler, 2002). For E. Fromm, the answer to a question what society is sane, is connected with moral traits of an individual and society as a whole, such as opportunity, responsibility, and obligation. A sane society is, first of all, a society in which nobody is a meanstowards an end of the other, but is rather the goal on oneself; a society in which nobody is used and uses oneself with the aim not to develop human capacities; a society in which a man is the central part, and his economic and political activities are directed to his own development; a society in which the individual is involved in social problems and solves them as his own; a society in which man's attitude to a neighbor is not separated from the entire self-other system (Fromm, 2005).

Socio-practical existence is multidimensional and formed by coordinates that meet the main types of people's vital activity and efforts, i.e. socio-ecological (life reproduction), socio-economic (resource recovery), socio-cultural (living standard recovery), and many others. A speed of changes which take place in subsystems of social and human life should be maximally agreed. This agreement is possible merely with the availability of a certain safety zone or a damper capable of smoothing turbulences dangerous both for the society and the environment on the whole. A damper is created by ideas, community ideals and values which form the basis for the choice of specific actions.

Social welfare is one of the universal categories the ideas and implementation of which create this safety zone. In this capacity, welfare is a regulatory mechanism. The concept of welfare is a regulator of the social tension and processes which reflects the integrating assessments of the quality of living and events in terms of a socialized individual included in the community of other people. And happiness of an individual depends on happiness of all other people that is proved by one of the eco-laws which runs that 'no joy can come from causing grief'. So, only orientation to the mutual achievement of welfare becomes the moral imperative of human life. And no matter, whomever mostly welfare depends from since it is already a shared responsibility. This mechanism is included in functioning of a civil society in the quality of social institution which expresses and protects personal interests in one's natural right 'everyone to his trade'.

Being an artifact, social welfare is recorded in the system of beliefs, assessments, rationales, requirements, and values of axiological dominants in man's existence. In this quality, welfare is a kind of chronotope of the social development, a spatiotemporal characteristic of normative-regulatory transformations. Therefore, social welfare is asociocultural policy directed to the establishment of axiological systems and norms that allow each person to feel safe. 


\section{Integrating or Axiological Basis for the Welfare and Sustainability Relationship}

A characteristic feature of modern civilization is a steady increase in the production and consumption. Just in the 20thcentury, the fuel consumption increased almost 30 times, and the industrial production more than 50 times (Sztompka, 2009). At the same time, the problem of poverty and ill-being is still the most relevant. How to solve it? According to A. Fromm, it is necessary to be conscious of pathological events occurring in society and a wish to changethe reality, and then real situation, values, and standards. In P. Sztompka's opinion, 'only by mutual agreement we can freeze some states important for our practical needs, treating them as single events, and speak of change or processes as the sequence of such frozen, 'discrete' points'(Sztompka, 1996).

Using the notion welfare, J. Habermas studied the idea of rationalization of actions. In his opinion, welfare is not available to a person who has no rationality, and it can be formed and conditioned both in the process of rationalization of one's own expectations and by rational interpretation of the environment (Habermas, 1995).

The methodology which unifies concepts of welfare and sustainability is the concept of the nature of social activities which are developed in the works of $\mathrm{H}$. Garfinkel. He founded that understanding of the social life by individuals occurs not only from the outside by accepting common cultural standards and values, but also from the inside. In Garfinkel's opinion, the social order is the product of one's own spontaneous activity which is created by participants of the social interaction allowing for rules and knowledge of the given cultural setting learned before and fixed by the notion tacit expectations (Garfinkel, 1967). Tacit expectations are the socially approved attitude to one or other actions observed by an individual and to which he/she assigns a rational meaning. This type of expectations is the basic latent structures of social life that can be revealed by highlighting a certain aspect of multiple properties of their definition. As A. Schweitzer states, the development of the concept of sustainability is directed to the acceptance of values oriented towards 'reverence for life'(Schweitzer, 1996). The original idea and the objective which unify social welfare and sustainability is man's development as the criterion of social progress implemented by choice broadening, increase of life durability, level of education, income, etc.

Recognition, discovery of one's own daemon (translated from Greek as 'godlike power, fate, god') and a further life organization in conformance with its laws is the foremost duty of each man from the moment of formation of civilization. Daemon comprises a reflectively critical man's attitude to himself and the world on the whole or a sensitivity to the truth phenomenon, moral conscience or sensitivity to welfare phenomenon, aesthetic sensibility or sensitivity to the beauty.A contravention of the principle of balance and proportion tends toward compensated justice, when the problem of the possibility of mankind existence by itself is sharply aggravated. Consensus achieved in social contacts does not accompany the activity, and requires a specific task and additional efforts for its accomplishment. To provide justice, it is necessary to form trust on the basis of positive personal and social purposes.

The process of sustainable development is complex, and a necessity of the purpose change is the priority provided that mankind will learn how to create and sustain constructive relations. Stability imperatives include the system of values allowing to assure a choice of decisions in favour of optimum proportions of equal possibilities for life of present and future generations judging from the priority of the safe character of measures taken for a prospective existence of mankind. In these terms, the concept of sustainability can be defined as a growing-point for new worldview orientations. One of the steps taken in this direction, is a closer attention to the problem of social responsibility for making decisions and their further implementation both at the individual and group activity levels.

The model of determined chaos includes a stable structural order at a macro-level formed by discrete chaos at a micro-level. A prototype of micro-organization regularity is archetypical symbols of 'labyrinth' or the world tree in which a transition to a higher level of the order is connected with transition to the whole new (evolutionary) level. So, the social welfare as a cultural universality, acts as a regulator of actions and control for the order in chaos.

\section{Conclusion}

The paper presents the rationale for the place and role of social welfare in the development of mankind. It is shown that welfare is incorporated in the development regulation mechanism that provides social process management. Social welfare as a multi-factor construct is represented by a synthesis of cause and effect.

On the basis of complementarity principle, argued is the statement on the interconnection between the sustainable development and welfare. It is proved that welfare is an ontological concept that estimates the social reality refracting during the processes of social being and acts as a universal resource capable of increasing the degree of stability of the social object that acts under conditions of indeterminacy.

The model of everyday practices is suggested to analyze the discussed processes allowing to study this problem 
addressing to the processes of needs satisfaction. In the modern world, the relevance of this approach is supported by the transformation of consumption from the simple use of consumer amenities to the instrument of social identity, sociocultural integration of the individual in society.

It was shown that regulation for social welfare is an ontological concept that measures the social reality change during the processes of the individual existence and acts in the capacity of the universal resource able to increase the degree of stability of the social object under conditions of uncertainty. Social welfare is a key factor of stabilization of social relations. Sustainability and welfare are interconnected processes unified by the principle of inter-complementarity when one supposes another. The continuous, sustainable development and social welfare along with the human rights protection can be provided by efforts concentrated on the human responsibility before himself and the society that is the most relevant problem of the modern world.

\section{Acknowledgement}

This work was performed by the authors in collaboration with Tomsk Polytechnic University within the project in Evaluation and enhancement of social, economic and emotional wellbeing of older adults under the Agreement No.14.250.31.0029.

\section{References}

Bourdieu, P. (1995). Struktury, habitus, praktika [Structures, habitus, practices]. In:Sovremennayasocial'nayateoriya [Modern social theory]: Bourdieu, Giddens, Habermas. Novosibirsk: Izdatel'stvoNGU, 16-39.

Diener, E., Lyubomirsky, S., \& King, L. (2005). The benefits of frequent positive affect: Does happiness lead to success? Psychological Bulletin, 131, 6, 803-855.

Durkheim, E. (1995). Jugements de valeur et jugements de realite. In: Sociology. Its subject, method, purpose.Moscow: Kanon.

Fromm, A. (2005). The sane society. The dogma of Christ.Moscow: AST.

Garfinkel, H. (1967). Studies in Ethnomethodology. New Jersey: Prentice Hall Inc.

Habermas, J. (1995). Demokratiya.Razum.Moral' [Democracy.Mind.Morality].Moskva: Izdatel'stvolTsAkademiya.

Maslow, A.(1999). Dal'niepredelychelovecheskoyprirody[The farther reaches ofhumannature].Moskva: Izdatel'stvoSmysl.

Rio+20. Date Views 12.08.2014. [Online] Available: http://www.csr-review.net/index/proon-planiruet-razrabotat-indeks-ustoychivogochelovecheskogo-razvitiya.html (August 12, 2012).

Schweitzer, A. (1996). Zhizn' ismysly [Life and meaning].Moskva: Izdatel'stvoRespublica.

Sztompka, P. (1996). Sociologiyasocial'nyhizmeneniy[The sociology of social change].Moskva: Izdatel'stvoAspekt.

Sztompka, P. (2009). The focus on everyday life: a new turn in sociology. Socis. 8, 3-13.

Toffler, A. (2002). Future shock. Moscow: AST.

Whitehead, A.N. (1990). Selected works on philosophy. Moscow: Progress. 